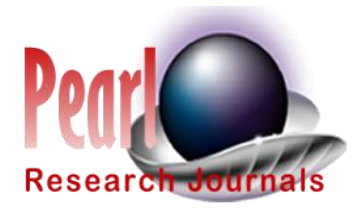

Research Journal of Educational Studies and Review

Vol. 6 (1), pp. 23-28, April, 2020

ISSN: 2449-1837

Research Paper

https://doi.org/10.36630/rjesr_20004

C2020 Pearl Research Journals

http://pearlresearchjournals.org/journals/rjesr/index.html

\title{
Advocacy for The Empowerment of Women Through Non- Formal Education in The Locality of Poli In Northern Cameroon
}

\author{
Patrice Martial AMOUGOU* and Christelle NGONNOHI DJEKOU
}

Accepted 16 March, 2020

Human and Social Sciences Laboratory of the National Institute of Youth and Sports of Yaoundé, Cameroon

\begin{abstract}
To concretize equality between men and women, the government of Cameroon has created Women Empowerment and the Family centers (WEFC). This was not only to fight against women's illiteracy but also to enable them to improve on their living conditions and reinforce their autonomy thus participate in the development of their community. This study's standing point was the fact that, despite all the equipment and the curricula geared towards non-formal education and literacy, the enrollment rate in WEFC of Poli remained low. This brought to light the main question which follows; "What could account for the low enrollment rate at the Poli women's empowerment center by women of this community?" To answer this question, a methodology that combined documentary research, direct observation and interview were made use of. From the analysis, we realized that many factors; both intrinsic and extrinsic accounted for this situation. To solve this problem, we came up with some suggestions.
\end{abstract}

Keywords: Empowerment, Non-formal education, Advocacy, Poli and Women.

Corresponding author.Email:amougoupat@yahoo.fr

\section{INTRODUCTION}

The constant quest for well-being has prompted the international community to define an institutional framework that militates in favour of education for all among other things. This means meeting the educational needs of all young people and adults by ensuring equitable access to adequate programs aimed at acquiring the knowledge and skills necessary for everyday life and, Improve in all its aspects the quality of education with a concern for excellence to obtain recognized and quantifiable learning outcomes for all, particularly with regard to reading, writing and calculation and the skills essential in every day's activities (Colcought, 2002). In the same vein, Sustainable Development Goal which aims at ensuring inclusive and quality education for all and to promote lifelong learning. In line with this vision, Cameroon has undertaken reforms that have resulted in the harmonization of content and output profiles of different types of education and training, to ensure the chances of operationalization of the gateways, especially between the formal and the non-formal education. In addition, the country has spared no effort to give adult literacy a prominent place in the national education system, with particular attention to the creation of structures for the supervision of girls and women who are out of school or undereducated, like the Center for the Promotion of Women and the Family (CPWF). However, despite the efforts made, the illiteracy rate remains high among women in the northern region of Cameroon, notably those in Poli, who face many difficulties hindering them from taking advantage of the training opportunities offered to them by the Women Empowerment and the Family Centre (WEFC). This study aimed to determine reasons for the poor attendance of WEFC of Poli by women who nevertheless faced many difficulties. It was specifically a question of identifying on the one hand, the endogenous and exogenous factors that prevented women from attending the WEFC, and on the other hand, suggested strategies 
of acceptance of a larger number of women to the offer of functional literacy by this WEFC.

\section{METHODOLOGY}

This study was done in two phases: a phase for data collection and another phase for analysing data collected.

\section{Population Studied and Sampling}

At this level, specifications were made about the target population on which the study was done and the sampling processed.

\section{Studied Population}

According to Grawitz (2000), the population of the study refers to all elements concerned by the subject of the study. Nkoum (2005), defines it as "all individuals whose characteristics match with the objectives of the research and can serve as a base to verify research hypotheses'. In this case, the population is made up of men and women of Poli, traditional rulers, the staff of the WEFC, religious and council authorities in Poli. The population is estimated at 3000 persons.

\section{Sampling}

It is the process of taking a sample from the researcher's population or a neighbouring population. In this study, the convenience sampling technique also known as accidental sampling was used. The choice of this sampling technique can be explained by the fact that Poli is a vast area and the persons in the study population are not easily spotted. These persons are spread out in the villages, making investigations difficult. To overcome this difficulty, those we came across was worked with as we carried out field investigation until our sample was representative of the main population and the different constituents of Poli. During this exercise, we had the valuable support of the council which provided us with a list of the main men and women associations, as well as the address of religious and traditional officials. A sample of 603 subjects, with 50 persons per village, among the 12 villages of Poli Sub-region was used. In details, we had 30 women, 15 men, 2 religious officials, and 3 representatives of traditional rulers, per village. In addition to these actors, the investigation also targeted the WEFC staff and the council mayor, making a representation rate of $23.97 \%$.

\section{Field Investigation}

Investigations were done in two phases, preinvestigation was done in August 2018 and the investigation proper was done between February and March 2019. Pre-investigation was done as an interview with free questions to officials of the Ministry of Women Empowerment and the Family (MINPROFF). This phase brought about objectivity to our problem and helped in carrying out this study. This phase was completed with data collected from observation. The investigation proper was based on information retrieval and individual/group discussions. Information retrieval consisted of consulting publications generally related to our themes. From our reading grid, we were able to give an account of the richness of this theme and the different perspectives in which it had been approached by other researchers, thereby outlining the originality to our perspective. As such, we consulted a collection of documents of the WEFC, the National Institute of Youth and Sports (NIYS), the Yaounde French Institute (YFI), the National Centre for Education (NCE), not leaving out online resources. For interviews, we had individual discussions with officials of the WEFC, council and administrative authorities, traditional rulers and religious heads. Group discussions were conducted in different villages with women and men. The task was to have the opinion of those stakeholders on the obstacles hindering women's access to training opportunities in the Poli WEFC.

\section{Validating Data Collection Tools}

Concern for quality and efficient results lead us to proceed first of all by the internal and external validation of our data collection tools. Internally, we had to guarantee the relevance and coherence of the tools. So, the first drafts were submitted to the laboratory team for appraisal, in-depth analysis of their formulation, coherence, relevance, and also for a better restructuring. Externally, it was focused on a limited sample of our target population, in the pre-test which enabled us to evaluate the fluidity of the axes and to consider remarks and observations. It's thanks to this exercise that the relevance of our data collection tool was proven. Then, as concerned verification of the interview grid, we investigated the traditional ruler of one of the villages and a member of one of the villagers' committees belonging to the men's network. Moreover, we interviewed 10 women we accidentally came across in the area. This exercise helped us to understand whether the questions were void of ambiguity and easily understood by the subjects. After then, we improved the tools we finally used from February to May 2019.

\section{Difficulties Encountered}

Even though data were effectively collected, it however remains a fact that we faced difficulties during our field investigation. The main hindrance was the reluctance of certain respondents, including women, to answer our questions.

\section{RESULTS}

General Knowledge of The Locality of Poli 


\section{Genesis}

Created in 1924. Poli (in local language, " fufuldé") is the plural of Pola which means pigeon. Oral sources indicated that the name was given by the Fulbé Muslim conquerors who arrived in the valley for their Islamization mission. Having noticed the impressive presence of pigeons, they decided to name the locality "Ouro Poli ", that is to say "village of pigeons". (Reizem, 2011).

\section{Geographic and Administrative Location}

Poli is located in a valley, surrounded by chains of mountains and hills. In addition to being the capital of the eponymous Sub-Division, Poli is also the capital of the Faro Division located $136 \mathrm{~km}$ from Garoua, capital of the North Region. The climate of Poli is tropical and of Sudanese variant with 5 months of rainy season and 5 months of dry season.

\section{Settlement Groups}

Poli is mainly occupied by the Dowato, characterized by their resistance to Islam, and the Fulbe, convinced Muslims. There are also Dupa, Samba, Bornouan, Hausa, Mafia, Moundang and Toupouri. The majority of the population are females.

\section{Main Activities}

The locality is favorable to agriculture, fishing, breeding and tourism. Field activities, particularly the cultivation of cotton, are the responsibilities of men, while domestic work and the cultivation of groundnuts are practices devolved to women.

\section{Social Organization}

The community is organized on the patriarchal norm and is strongly controlled by the male sex where the man is the head of the family.

\section{Services}

The locality of Poli benefits from the presence of decentralized state services. Civil and military public administrations are represented. The education sector is represented by 5 establishments including a nursery school; a bilingual nursery school; 3 government primary schools, a government bilingual primary school, a Protestant primary school, a Catholic primary school, a government high school, a government technical high school and a government bilingual secondary school. In addition to these structures of classical education, it should be noted that there are two non-formal education centers, namely a Multipurpose Youth Empowerment Center (MYEC), and a Women Empowerment and the Family Centre (WEFC).

\section{The Relevance of The Women Empowerment and The Family Centre}

Faced with the observation of the sinking of the national social fabric, and particularly families in the vicious circle of poverty following the economic recession, the Ministry of Women Empowerment proceeded to the evaluation of its operational technical unit which is the House of the Woman. From the shortcomings observed, the need arose to widen the missions assigned to this structure, which resulted in the transformation of women's houses into CPFFs following decree $N^{\circ} 98 / 068$ of May 04 1998, organizing the Ministry of the Status of Women, which makes them specialized technical units. Their organic framework is determined by decree $N^{\circ} 2000 / 001 / P M$ of January 04,2000 , with slight adjustments introduced by decree $N^{\circ} 2005 / 008$ of March 28, 2005 relating to the organization of MINPROFF. This is how the CPFF of Poli took shape in 2007, thanks to the Family Income Improvement Program of the Northern Regions of Cameroon with French acronym PARFAR.

\section{In Terms of Infrastructure}

The WEFC of Poli has a block of twenty-three (23) pieces. Five (5) compartments reserved for toilets, a hall, a kitchen, two (2) rooms which serve as shops, two (2) other rooms which serve as pharmacy and treatment room, five classrooms intended for theoretical courses and practical, the other rooms serve as administrative offices and finally a large multipurpose room that satisfies the needs for various meetings (conferences, seminars, parties, etc.) in the city.

\section{At the Administrative Level}

The Center is administered by a board of directors which was organized by the Senior Divisional Officer's Order N - 087 / AP / D46 / SAAJP of May 17, 2013. This board is the decision-making body of the center. The WEFC management ensures the general coordination of the activities of the center's services. It includes the administrative and financial affairs unit; the educational support and monitoring unit; the guidance and counseling unit and the health unit.

\section{In Terms of Education}

membership of the center is based on the study of files, with a registration fee of 2,000 FCFA and an annual pension which varies from 10,000 to 12,000 FCFA depending on the sector. Training takes place in two ways; that is, permanent and for some, "à la carte ". The duration for continuous education is generally one year. At the time of the investigation, the WEFC of Poli had two trainers commissioned by the State and four temporary workers. The training courses were: IT, textiles and clothing industry, hotel management and catering, project management and literacy. The trainers did not 
only ensure the teaching load, but also the missions of raising awareness and mobilization of women with a view to greater acceptance of the center's activities. In 2019, 26 women enrolled at the WEFC of Poli; 24 learners completed their training, while 2 dropped out. In detail, 10/10 in IT; 12/12 in Textile and Clothing Industry and 2/2 in literacy completed their training. The 02 ladies enrolled in hotel management and catering abandoned the training. It also appeared that this Center faced several difficulties, the most significant of which were material and financial, which made it difficult to achieve the training objectives. Human resources could not be outdone, with a real deficit in terms of quality and number.

\section{Factors for the Low Attendance of the Poli C WEFC by Women}

\section{Endogenous Factors}

The reasons mentioned by the respondents were related to the low level of income, the lack of information on the WEFC, the unavailability of women and the respondents' perception of the WEFC. Respondents believed that the WEFC registration fee was high. In addition, the economic profile of these women who mainly operated in agriculture did not allow them to have enough money to support their families and to engage in training activities. This situation was confirmed by the statements of the men and local officials interviewed. The women also declared that they were not informed of the activities carried out at the WEFC, despite the efforts made by the management of this establishment to communicate in churches and through "door to door". The survey also revealed the preponderant place of the family in the Poli communities. In fact, they insistently emphasized in their remarks on the need to ensure a constant presence of women at home, to assume family responsibilities. All of the women interviewed affirmed that maternity and taking care of the immediate family constituted an obstacle for them to engage in training. From another angle, the calendar of training at the WEFC discouraged women who were enrolled because; the time devoted to training activities did not allow them to equally attend to other important occupations. The courses took place from 8 am to $3: 30$ pm every Monday to Friday. During our interviews, seven (7) women aged 45 and above, who left elementary school, did not feel competent enough to undergo training. These women had the impression of being different (apart), lacking the intellectual capacities necessary to be able to carry out learning properly.

\section{Exogenous Factors}

The external factors which prevented women of Poli from attending the WEFC of their locality were related to the distance from the place of training, the seasonal calendar, the habits and customs, the mechanisms of employment support and the lack of qualified staff.
Located on the outskirts of the city center, the WEFC in Poli is somewhat landlocked. This distance from the city discouraged the women's population in the area, who did not agree to travel miles to acquire training; "this is what we were told by the women of Kongle, a locality located 20 kilometers from the WEFC in Poli". These women would like to benefit from the WEFC training offers but, the distance and the lack of means of locomotion did not allow them to get up in the morning and get there in time to follow the courses given and then return home in good conditions. To this difficulty, are added the transport conditions as in the vast majority of rural areas in Cameroon where public transport is rare, moving to this place of training becomes difficult or even impossible. This situation, in the long run, pushed these women to be tired and abandon their training cycle at WEFC. Women also said they could not reconcile training and work in the fields. Agriculture is their main source of subsistence and income, it becomes essential for them and their families to capitalize on the rains which only arrive in this locality once a year. Hence, the inevitable choice to give priority to rural activities to the detriment of training. The mistreatment suffered by women by their spouses partly explains the low rate of adherence of the fairer sex to the training activities offered by the CPFF. For these men, the mastery of their rights to marital status undoubtedly led women to start demanding civil marriage and the advantages of the monogamous regime. These men, who knew that women did not appreciate cohabitation, became skeptical when it came to allowing them to emancipate themselves by training. Those who completed training at WEFC had no job prospects and were systematically exposed to the discouragement of being trained. In addition to this situation, they deplored the quality of the training staff who, according to them, were not prepared to take charge of an adult client.

\section{DISCUSSION}

In the sense of UNESCO, literacy is primarily organized to transmit the ability to identify, understand, interpret, create, communicate and calculate using printed or written materials associated with variable contexts. Literacy involves continuity of learning to enable individuals to achieve their goals, develop their knowledge and potential and participate fully in their community and their society as a whole. Literacy is therefore understood as any activity whose focus is reading, writing and calculation, as a stage in a lifelong learning process, which must lead to creative expression and conceptual problem-solving skills. Its functional approach aims to acquire knowledge by a given group in relation to its socio-economic activities. It induces a postliteracy phase which is the set of possible uses of the literacy skills, the action of consolidating the skills of the initial literacy phase, extended to socio-economic activities that supplement educational activities. 
UNESCO defines it as the set of measures and actions designed to enable newly literate people to permanently reinvest the knowledge and skills acquired in their personal, family and community environment, so that they can face their problems, personal or professional, go beyond them and commit, through new acquisitions, to go further and, through other achievements, to be part of a continuous process of permanent learning. Because of these developments, the international community is now interested in the use of these skills for socioeconomic development, as well as civic awareness and critical thinking, the bases of personal and social evolution. It is this role that the State of Cameroon seems to assign to the WEFCs, under the terms of Decree No. $2000 / 001$ / PM of January 4, 2000, relating to the organization and operation of centers for the promotion of Women and the Family, specialized technical units responsible for the promotion of women. These establishments are aimed to solve the problem of gender equality and women's autonomy through training. They thus, constitute an appropriate response to the lack of supply in the formal education system which according to Coombs (1973), writing about New paths to learning for rural children and youth, "could not adapt to social values and the conditions of the environment ".

In view of the results of the survey carried out within the framework of this article, Ahodehon (2005) in his dissertation based on Problem of the contribution of literacy to the improvement of community health in urban areas: the case of Cotonou in the Republic of Benin and Musa (2005) in Non-formal education in the educational and socio-economic contexts of the DR Congo: Exploratory study on the legal status and attitudes of the inhabitants of Kinshasa, proposed an improvement of the education and training system, by stimulating the spirit of creativity and individual business, as well as the development of personalized training that takes into account the realities of environments and sectors with high job content. In this regard, the work of Mezene (2011) on the Empowerment of women through socioprofessional integration: study conducted at the CPFF of Abong-Mbang in East Cameroon and Mbezele (2013) on the Contribution of the centers for the advancement of women and the Family in improving the living conditions of women in urban areas: a study carried out at the CPFF in Tsinga, shows the place of these training centers in the processes of the empowerment of women and their participation in development.

In addition, the course of Cameroon towards emergence, commanding the provision of all human capital including women who should more than ever benefit from educational offers within their reach, like WEFC. It becomes imperative with Nkassa-Nang (2011) dealing with Religious associations and socio-economic integration of Cameroonian women: a study carried out in the Christian association of women in the YaoundéSion parish of the consistory Nkol-Mvolan (East Cameroon) and Roba (2017) in his dissertation title Contribution to the empowerment of women at CPFF in
Poli, that measures are taken for its emancipation and its promotion. In view of the above, proposals are made relating to the optimization of advocacy aimed at frequenting the Women Empowerment and the Family Centre of Poli by women in this locality. As a first step, the Ministry of Women Empowerment and the Family, responsible for the WEFC should proceed with: Audits or evaluations to identify the needs of the WEFC and provide solutions. These audits can also lead to the development of the WEFC development plan for Poli.

The effective transfer of skills to provide the WEFC of Poli with human resources to enable it to achieve its objectives. Capacity building for teaching staff by organizing seminars and training workshops, in line with the needs of the center. Supporting the WEFC in signing partnership agreements with local public and private institutions, to increase financial and material support. WEFC managers at Poli should at their level make the training offer more attractive, this can be done through the DE concentration of certain training from villages to villages, to arouse the commitment of men who are still reluctant to accept that their wives should be trained at WEFC. The traditional chiefs, auxiliaries of the public administration of the State, could in their way accompany the realization of the missions of the Center. Their role would then be to sought particularly in the field of raising awareness among families on the importance of training local women in the WEFC, with a view to their selfdetermination and their empowerment. As for women, they can organize themselves in associations to think of their actions. These women can create activities within their associations to attract the support of men in their projects, thus, becoming actors of choice on the sociopolitical and economic level of the locality; promoters of a new social order. For their part, men must not only get rid of the perception of the training of women as an insidious mechanism for reversing an order of dominance but also, and above all subscribe to the requirements of the international community that Cameroon has adopted, in terms of training, education, empowerment and self-determination of women and girls.

\section{CONCLUSION}

The purpose of this work was to empower women through education. The problem posed here was that of low attendance of the WEFC in Poli by the women of this locality. The objective was to determine the reasons why the WEFC in Poli is not frequently visited by women from this locality who nevertheless face many difficulties. This led to a methodological approach based on observation, documentary research and semi-structured interviews, with a sample drawn from the WEFC administration, village chiefs, religious authorities as well as women and men of Poli. Thus, the investigation revealed a set of endogenous and exogenous factors responsible for this situation. To increase the attendance of the Center by 
women, several proposals were made particularly related to, the need to make the importance of this structure more easily known to women, to create partnerships to support the members, to sensitize the men of Poli to encourage their women to attend the WEFC.

\section{REFERENCES}

Colcought $C$ (2002). Education for All: the world is it on the right track? Rapport mondial de suivi sur l'EPT, éditions UNESCO, Paris. Pp.319.

Coombs $P$ (1973). New paths to learning for rural children and youth. New York: International Council for Educational Development. P. 133.

Grawitz M (2004). Lexicon of social sciences, 8th ed Paris, Dalloz. P. 422.

NKoum BA (2005). Initiation to research, a professional necessity. UCAC Press, Memento. Yaounde. Pp. 179.

Ahodekon SC (2005). Problem of the contribution of literacy to the improvement of community health in urban areas: the case of Cotonou in the Republic of Benin. Unpublished dissertation in partial fulfillment of the requirements for the degree of the end of the 4th academic year, University of Abomey-Calavi, Benin.

Mbezele EJ (2013). Contribution of the centers for the advancement of women and the Family in improving the living conditions of women in urban areas: study carried out at the CPFF in Tsinga. Unpublished dissertation in partial fulfillment of the requirements for the degree of Senior Youth and Action Counsellor, National Institute of Youth and Sports, Yaoundé, Cameroon.

Mezene MC (2011). Empowerment of women through socioprofessional integration: study conducted at the CPFF of AbongMbang in East Cameroon. Unpublished dissertation in partial fulfillment of the requirements for the degree of Youth and Action Counsellor, National Institute of Youth and Sports, Yaoundé, Cameroon.
Musa AD (2005). Non-formal education in the educational and socioeconomic contexts of the DR Congo: Exploratory study on the legal status and attitudes of the inhabitants of Kinshasa. Unpublished dissertation in partial fulfillment of the requirements for the degree of DEA, University of Kinshasa.

Nkassa-Nang MN (2011). Religious associations and socio-economic integration of Cameroonian women: study carried out in the Christian association of women in the Yaoundé-Sion parish of the consistory Nkol-Mvolan (East Cameroon). Unpublished dissertation in partial fulfillment of the requirements for the degree of Senior Youth and Action Counsellor, National Institute of Youth and Sports, Yaoundé, Cameroon.

Reizem A (2011). Functional literacy in mother tongues: an analysis of the approach of the center for the advancement of women and the family of Poli. Unpublished dissertation in partial fulfillment of the requirements for the degree of Senior Youth and Action Counsellor, National Institute of Youth and Sports, Yaoundé, Cameroon.

Roba C (2017). Contribution to the empowerment of women at CPFF in Poli. Unpublished dissertation in partial fulfillment of the requirements for the degree of Senior Youth and Action Counsellor, National Institute of Youth and Sports, Yaoundé, Cameroon.

Cameroon (1998). Decree $n^{\circ}$ 98/068 of May 04, 1998 on the organization of the Ministry for the Status of Women.

Cameroon (2005). Decree $n^{\circ}$ 2005/008 of March 28, 2005 on the organization of the Ministry of Women and Family Welfare.

Cameroon (2000). Decree $n^{\circ}$ 2000/001 / PM of January 04, 2000 establishing, organizing and operating the Centers for the Promotion of Women and the Family.

Cameroon (2013). Prefectural decree $n^{\circ} 087$ / AP / D46 / SAAJP relating to the designation of the members of the Center for the Promotion of Women and the Family management board of Poli of May 17, 2013. 